\title{
Influência do déficit de atenção e hiperatividade na aprendizagem em escolares
}

\section{The attention-deficit byperactivity disorder influence in schooler's learning}

\author{
Claudia Maria Gouveia Muzetti ${ }^{[a]}$, Maria Cecília Zanoto de Luca Vinhas ${ }^{[b]}$
}

[a] Discente do curso de Pós-Graduação em Educação Especial e Inclusiva (modalidade EAD) do Centro Universitário Barão de Mauá, Ribeirão Preto, SP - Brasil.

[b] Docente do curso de Pós-Graduação em Educação Especial e Inclusiva do Centro Universitário Barão de Mauá, Ribeirão Preto, SP - Brasil, e-mail: deluca_vinhas@yahoo.com.br

\section{Resumo}

O Transtorno de Déficit de Atenção/Hiperatividade é um distúrbio neurocomportamental com prevalência em crianças e adolescentes, trazendo consequências no aprendizado na fase de aquisição e desenvolvimento, causando dificuldades emocionais e sociais. Fatores ambientais e genéticos estão relacionados ao transtorno e o diagnóstico precoce é uma das formas de tratamento. A questão fundamental que nos leva a estudar este tema está vinculada na prática pedagógica, onde percebemos que existem fatores que podem influenciar e prejudicar o desempenho dos educandos, incluindo diversos problemas tanto de ordem familiar, social e principalmente os que afetam a atenção. Assim, nossos objetivos visam a compreender esse transtorno, identificar os sintomas, causas, e propor estratégias de intervenções, para manejar melhor os conhecimentos e favorecer uma melhor atenção e amparo educacional a essas crianças. Realizamos pesquisas bibliográficas em diversas fontes como: Scientific Electronic Library Online (SciELO), PubMed, entre outras, buscando informações para compreender os diferentes aspectos associados (comportamento e relacionamento da criança hiperativa), possibilitando alternativas para um melhor atendimento na área educacional.

Palavras-chave: Transtorno de déficit de atenção e hiperatividade (TDAH). Aprendizagem. Escolares.

\section{Abstract}

Attention-Deficit Hyperactivity Disorder is a developmental disorder, largely neurological in nature, with prevalence in children and adolescents, which brings consequences in learning, in the cognitive acquisition and development 
phase, causes emotional and social difficulties. The environmental and genetic factors are directly related to the disorder and so the precocious diagnosis is one way of ADHD treatment. The fundamental subject that leads us to study this theme is linked to the pedagogic practice, where we notice the existence of factors which can influence and harm the students' acting, as much as the problems of family, social order and, mainly, the ones that affect the attention. Thereby, our purposes seek to understand this disorder, to identify the symptoms, the causes and consequences, to propose interventions to articulate the knowledge better and to dedicate larger attention and education help to those children. We accomplished bibliographical researches in several sources, such as: Scientific Electronic Library Online (SciELO), PubMed, among others, looking for information to understand the different aspects of the hyperactivity (the behavior and the relationship of the hyperactive child), making possible alternatives for a better service in the education area.

Keywords: Attention-Deficit Hyperactivity Disorder (ADHD). Learning. School period.

\section{Introduçáo}

Quando se pensa em uma estrutura educacional bem organizada, inclui-se nesse contexto a finalidade primordial de contribuir com a aprendizagem e o desenvolvimento do ser humano como um todo. Isso implica diversos dilemas que a educação proporciona, como, por exemplo, o "moldar" o indivíduo de acordo com padrões e condutas previamente estabelecidos, mas em constantes transformações. Ao mesmo tempo, remete ao profissional da educação a exigência de constantes adaptações em prol desse objetivo.

O que se percebe na atualidade é que diversos problemas podem estar associados à aprendizagem, envolvendo o universo dos sujeitos (educandos e educadores) e o objeto (o que se pretende "oferecer" e ser apreendido pelo educando). O transtorno do déficit de atenção e hiperatividade (TDAH) constitui um grande desafio para pais, professores e profissionais; os pais não sabem como agir e que postura assumir diante dos problemas que surgem com seus filhos em idade escolar e os professores, com restritas informações sobre o assunto, ficam na mesma situação e muitas vezes não sabem o que fazer e que atitudes tomar diante dos insucessos do educando na sala de aula. A questão fundamental que propiciou o estudo deste tema está vinculada à prática pedagógica, por meio da qual se percebe a existência de fatores que podem influenciar e prejudicar o desempenho dos educandos, como os diversos problemas tanto de ordem familiar, social e, principalmente, os que afetam a atenção.

Desse modo, os objetivos foram delineados visando a compreender o TDAH, identificar os sintomas, causas, consequências e, posteriormente, promover estratégias de intervenções na prática pedagógica em relação às principais dificuldades que podem ocorrer no processo ensino-aprendizagem. Pensa-se que, ao entender as influências sobre a aprendizagem e como lidar com este transtorno, bastante frequente em sala de aula, é mais fácil articular os conhecimentos para favorecer uma maior atenção e amparo educacional às crianças que apresentam o problema. Foram realizadas pesquisas bibliográficas, em diversas bases, tais como Scientific Electronic Library Online (SciELO), PubMed, entre outras fontes, buscando informações necessárias para compreender os diferentes aspectos da hiperatividade, tais como comportamento e relacionamento da criança desatenta e hiperativa no ambiente escolar, possibilitando, assim, alternativas para um melhor atendimento na área educacional.

\section{Que transtorno é esse?}

O Transtorno do Déficit de Atenção e Hiperatividade (TDAH) é atualmente considerado um distúrbio do neurodesenvolvimento infantil, que pode persistir ao longo da vida em mais da metade dos casos. Os Transtornos de Aprendizagem (TA) em crianças diagnosticadas com TDAH podem ser justificados em virtude do processo de atenção ser essencial e de primordial importância para a adequada aprendizagem na fase de aquisição e desenvolvimento de linguagem. Dessa forma, crianças com limitações prematuras para se comunicar deparam-se com problemas de relacionamentos interpessoais e correm os riscos de apresentar transtornos específicos 
de aprendizagem da leitura e da escrita. O TDAH foi indicado como motivo de piora do prognóstico escolar para crianças portadoras de TA, mais do que a comorbidade com transtornos internalizantes, como a depressão. Entre as razões declaradas frequentes causadoras do mau desempenho escolar, estudos e ou autores citam a própria disfunção neuropsicológica desse transtorno. Entretanto, a importância da identificação do TA e comorbidades, como o TDAH, está intimamente associada com o sucesso de medidas terapêuticas e estratégicas educacionais (Benczik, 2008).

Rohde, Barbosa, Tramontina e Polanczyk (2000) relatam que as primeiras referências encontradas na literatura médica sobre aos transtornos hipercinéticos apareceram em meados do século XIX. Entretanto, o quadro clínico começou a ser descrito de uma maneira mais sistemática somente no século XX.

Para os mesmos autores citados anteriormente, o impacto dessa síndrome na sociedade é enorme, considerando-se o alto custo financeiro, estresse na família, prejuízo nas atividades acadêmicas e vocacionais, bem como os efeitos negativos que repercutem na autoestima das crianças e adolescentes. Estudos demonstram que crianças com diagnóstico de TDAH apresentam maior risco de desenvolverem outras doenças psiquiátricas na infância, na adolescência e na idade adulta, como comportamento antissocial, problemas com uso de drogas lícitas e ilícitas e transtorno de humor e ansiedade.

O TDAH é um transtorno extremamente pesquisado e com validade superior à da maioria dos transtornos mentais, inclusive a de muitas condições médicas. Rohde et al. (2000) caracterizam o TDAH em dois grupos, levando em consideração a apresentação dos sintomas: desatenção, hiperatividade (agitação e impulsividade). A maioria das crianças que apresentam o TDAH do grupo desatento possui uma grande dificuldade em prestar atenção em detalhes, cometem erros por descuido e têm problemas ao concentrar-se em tarefas e/ou jogos e, por não conseguirem prestar atenção ao que lhes é dito, dão a impressão de estarem no "mundo da lua", além disso, dificilmente terminam algo que começam a fazer, não conseguindo também seguir as regras e as instruções; são desorganizados com materiais e tarefas, evitando atividades nas quais é exigido um esforço mental maior; costumam perder coisas importantes, frequentemente se distraem com estímulos que não têm nenhuma relação com o que estão realizando.

Nas crianças pertencentes ao grupo da hiperatividade (impulsividade), observa-se uma movimentação exagerada com as mãos e pés quando estão sentados, e dificuldades de se manterem assim por muito tempo; elas parecem ter uma sensação interna de inquietude, por isso chegam a pular e a correr demasiadamente em situações inadequadas; ao jogar ou brincar, são muito barulhentas, agitadas, falam demais, respondem às perguntas quase sempre antes de terem sido terminadas, não suportam esperar a vez e intrometem-se nas conversas e jogos alheios constantemente.

Como diagnóstico de TDAH são necessários, pelo menos, seis sintomas de desatenção e seis dos sintomas de hiperatividade (impulsividade), e é bastante comum confundir com sintomas de outras patologias associadas.

Em relação à etiologia, Rohde (2003), citado por Viaro, 2008), considera que o TDAH é uma síndrome heterogênea, pois depende de fatores genético-familiares, adversidades biológicas e psicossociais. Assim sendo, o TDAH ocorre do resultado de uma disfunção neurológica no córtex pré-frontal, graças, em parte, a uma deficiência do neurotransmissor dopamina. Em algumas pessoas que possuem o transtorno, quando tentam se concentrar, a atividade do córtex pré-frontal diminui, ao invés de aumentar (como acontece com sujeitos do grupo de controle de cérebros normais), dessa forma surgem muitos sintomas, como fraca supervisão interna, pequeno índice de atenção, distração, desorganização, hiperatividade (apesar de alguns dados na literatura relatarem que somente a metade das pessoas com o transtorno sejam realmente hiperativas), problemas de controle de impulso, dificuldade de aprender com erros passados, falta de previsão e adiamento. Algumas pesquisas apontam que a pessoa com TDAH, ao tentar se concentrar, apresenta uma piora na atividade do córtex pré-frontal, quando este está hiperfuncionante, não é capaz de filtrar adequadamente os estímulos sensoriais que chegam até o cérebro e, como resultado, esses estímulos em demasia bombardeiam o cérebro, levando-o ao mau funcionamento.

Os mesmos autores citados anteriormente comentam que o segundo fator etiológico abrange a causa biológica com forte influência genética. Os estudos, apesar dos resultados conflitantes, indicam uma associação do TDAH com complicações durante 
a gravidez e o parto, pós-maturidade fetal, duração prolongada do parto, sofrimento fetal, baixo peso ao nascer e hemorragia pré-parto. Além do mais, os fatores ambientais também podem estar associados ao TDAH, pois estudos mostram que certos problemas, tais como desentendimentos familiares, presença de transtornos mentais nos pais, baixo nível de educação materna, pobreza, filhos de pais solteiros, conflito paternal crônico, abuso sexual e outros, constituem alguns desses fatores.

Conforme Rohde e Halpern (2004), a desatenção, a hiperatividade ou a impulsividade, como sintomas isolados, podem ser resultado de problemas relacionais presentes na vida das crianças, de sistemas educacionais inadequados, ou mesmo estarem associados a outros transtornos comumente encontrados na infância e na adolescência. Portanto, para diagnóstico do TDAH é sempre necessário contextualizar os sintomas a partir da história de vida da criança. É importante salientar que a apresentação clínica pode variar de acordo com o estágio de desenvolvimento, ou seja, os sintomas existentes na fase inicial da criança podem ser diferentes dos apresentados pelo adolescente. Segundo eles, o TDAH pode ser dividido em três tipos: a) TDAH, com predomínio de sintomas de desatenção; b) TDAH, com predomínio de sintomas de hiperatividade/impulsividade; c) TDAH, combinado. O TDAH com predomínio em desatenção apresenta um nível mais alto de isolamento social e retração, e grandes dificuldades de aprender habilidades sociais de forma apropriada. As crianças com TDAH com predomínio de sintomas de hiperatividade/impulsividade são mais agressivas que as pertencentes a um dos outros dois tipos, tendem a apresentar altas taxas de rejeição pelos colegas e sofrer de impopularidade. Já o tipo combinado apresenta como característica, um maior comprometimento no funcionamento global quando comparado aos dois outros grupos.

\section{As bases biológicas do TDAH}

A inesperada contradição entre a "boa" educação recebida e o "mau" comportamento das crianças traz à tona, na virada do século, as observações do médico George Frederic Still sobre a influência da genética e da biologia nas causas do DDA (déficit de atenção) e a teoria de William James, psicólogo americano que acreditava que os déficits ocorriam por uma relação causal como um defeito neurológico subjacente (síndrome de desconexão no córtex cerebral). Assim, em 1934, Eugene Kahn e Louis H. Cohen retomam as observações deixadas por Still e James. Kahn e Cohen concluem que as características básicas para a tríade diagnóstica dos sintomas de DDA são: distratibilidade, impulsividade e inquietação. Em 1937, Charles Bradley relatou o êxito do uso do fármaco benzedrina, um estimulante, para tratar as crianças com distúrbios de comportamento. No início da década de 1970, a definição da síndrome passou a incluir não apenas a hiperatividade evidente no comportamento, mas também os sintomas mais sutis de distraimento e impulsividade (Hallowell \& Ratey, 1999, p. 320-323).

Kornetsky (1970), comentado por Hallowell e Ratey (1999), propôs a hipótese de Catecolamina para a Hiperatividade. As catecolaminas são compostos que incluem os neurotransmissores noradrenalina (norepinefrina) e dopamina sintetizados a partir do aminoácido tirosina. Ele concluiu que o DDA pode ser provocado por uma baixa produção desses neurotransmissores. Talvez seja o regulador exclusivo do DDA, mas é correto afirmar que muitas drogas atuam sobre a norepinefrina e dopamina, o que representa um avanço na busca pelo tratamento mais específico do DDA, embora os estudos das duasúltimas décadas não tenham conseguido documentar o papel específico das catecolaminas no DDA. Mattes e Gualtieri, citados por Hallowell e Ratey (1999), especularam que os lobos frontais estariam envolvidos no distúrbio do déficit de atenção em razão da similaridade entre os sintomas do DDA e as síndromes do lobo frontal resultantes de traumatismos ou lesões nas áreas frontais. Muitos sintomas do DDA surgem porque o cérebro perde a capacidade de "pisar nos freios" de maneira satisfatória, em razão de uma perturbação nos processos inibitórios do córtex, ou camada externa do cérebro. Sem essa inibição o cérebro não é capaz de bloquear as respostas impróprias, fazendo com que a impulsividade e hiperatividade emerjam.

Muitos medicamentos já foram utilizados para o tratamento desse transtorno e diversas teorias apresentadas para apontar as suas causas, muitos pesquisadores e especialistas estão envolvidos na busca por uma solução e por respostas. Os medicamentos empregados para tratar o DDA incluem os estimulantes ritalina, cybert, dexedrina e os antidepressivos tricíclicos, que agem nos sistemas da catecolamina e serotonina de modo a corrigir os processos atencionais desregulados e desacelerar 
o fluxo de vida acelerado. As drogas aumentam os níveis dos neurotransmissores, proporcionando uma maior disponibilidade do neurotransmissor em questão para uso pelo cérebro. Os estimulantes criam um equilíbrio na química das regiões frontais do cérebro sem que seja preciso que o sistema inteiro se modifique, permitindo um controle tônico dos sistemas frontais do córtex cerebral. Porém, já sabemos que esse distúrbio constitui um problema neurológico e precisa ser tratado, mas, infelizmente, não há uma cura definitiva, há apenas mecanismos para amenizar o problema, como, por exemplo, o uso de medicamentos, acompanhamento clínico e psicológico, apoio familiar e, principalmente, muita informação e compreensão sobre o assunto por parte dos pais e professores, pois estão diretamente ligados ao desenvolvimento das crianças e são responsáveis por ele (Hallowell \& Ratey, 1999, p. 327-337).

Rohde, mencionado por Viaro (2008), também relata que as intervenções psicofarmacológicas giram em torno da terapia com psicofármacos para o TDAH e ainda depende das comorbidades presentes. O fármaco mais utilizado é o metilfenidato (ritalina), um estimulante que inibe a impulsividade e reduz a hiperatividade, melhorando os níveis de atenção. A dose terapêutica normalmente se situa na faixa de 20 a $60 \mathrm{mg} / \mathrm{dia}$. Os principais efeitos secundários no início do tratamento são a insônia e a falta de apetite, o que pode piorar ainda mais o mau comportamento da criança nessa fase de tratamento.

Outros estudos demonstram uma prevalência significativamente maior de uso abusivo/ dependência de drogas em adolescentes com TDAH que não foram tratados com estimulantes quando comparados a jovens com o transtorno e que foram tratados com medicamentos, entretanto, vários estudos apontam a possibilidade de uso inadequado dos estimulantes por pessoas não portadoras do transtorno. Esses fatores e informações são importantes para podermos perceber o universo em que a criança portadora de TDAH está envolvida e assim delinearmos nossas estratégias de apoio eintervenção.

\section{Intervençôes para auxiliar o desempenho cognitivo}

Segundo Fullan (2000), citado por Viaro (2008), em crianças com o diagnóstico de TDAH, o desenvolvimento cognitivo deve ocorrer com a ajuda de todos os envolvidos no processo: especialistas, médicos, professores, coordenadores pedagógicos e pais. Para que haja sucesso escolar das crianças com TDAH há a necessidade de vários tratamentos e intervenções.

Goldstein (2007), mencionado por Viaro (2008), cita três tipos de intervenções: a primeira é o uso de medicamento; a segunda e a terceira são técnicas, não médicas, as quais pais e professores devem compreender e utilizar. Uma delas refere-se às formas de gerenciar eficazmente o ambiente doméstico e escolar da criança para reduzir os problemas associados à hiperatividade.

Existem ainda fatores importantes que dificultam o aprendizado das crianças com TDAH. Hallowell e Ratey (1999) comentam que o sofrimento causado porum distúrbio de aprendizagem associado ao déficit de atenção (DA) reside não somente no esforço da pessoa para "funcionar" cognitivamente, mas nas "desconexões" que ela pode sofrer em relação à linguagem e ao pensamento, à expressão e à criatividade, à leitura e articulação das palavras, assim como na relação com as pessoas e as formas de expressar seus sentimentos, além disso, alguns dos prazeres proporcionados pelo transtorno são as variações fantasiosas e criativas que proporcionam. Enquanto a criança com dislexia e DA pode gaguejar, tropeçar ou se revirar enquanto desliga da palavra, da página ou da pessoa, ela também pode se superar porque pode deparar com algo novo e motivador, por isso, é vital que a preservemos da vergonha, da crítica, do derrotismo e da desvalorização.

Quando se lida com o TDAH é importante observar que ele está associado a outras dificuldades de aprendizado. Na visão de Pennington, citado por Hallowell e Ratey (1999), esse transtorno constituium entre vários distúrbios de aprendizagem. $\mathrm{Na}$ grande maioria das vezes um distúrbio de aprendizagem está relacionado a um problema no sistema neuropsicológico que afeta de modo adverso o desempenho escolar. Uma criança normal pode apresentar um baixo desempenho sem ter um distúrbio de aprendizagem, em razão de outros fatores emocionais ou sociais.

Existem vários distúrbios que afetam a aprendizagem, incluindo nesse grupo o retardo mental, a dislexia, os transtornos do desenvolvimento da linguagem, dificuldades de aprendizagem no hemisfério direito (problemas com matemática, caligrafia, artes e cognição social), autismo e memória adquirida (decorrentes de traumatismo craniano ou 
convulsão). O próprio TDAH é um tipo de distúrbio de aprendizagem e pode ser acompanhado de outros transtornos como a dislexia ou distúrbio de memória adquirida, ou por dificuldade específica de aprendizagem relacionada à matemática (discalculia), ortografia, etc.

O TDAH afeta todas as áreas da cognição e tende a exacerbar qualquer dificuldade específica de aprendizagem, porém, não inviabiliza por completo qualquer função cognitiva, é bem mais amplo que isso. $\mathrm{O}$ distúrbio de aprendizagem mais comum é a dislexia, que é considerada uma dificuldade de ler ou escrever na língua nativa e não pode ser explicada por qualquer outra causa, como escolaridade limitada, visão ou audição fracas, lesões cerebrais ou retardo mental. Alguns disléxicos têm dificuldades com a ortografia, outros invertem as letras, outros preveem letras ou sons de forma incorreta, o que dificulta a leitura das palavras (Hallowell \& Ratey, 1999, p. 203).

Os mesmos autores anteriormente citados comentam que os cérebros dos disléxicos parecem ser diferentes dos cérebros normais, contendo nódulos anormais no córtex cerebral que podem interferir no modo como o cérebro percebe e processa os fonemas ou partículas sonoras que formam as palavras. O processamento fonológico comprometido leva à dificuldade de leitura, ortografia e escrita, características da dislexia. Os sintomas primários do TDAH (atenção irregular, impulsividade e inquietude), por exemplo, podem dificultar a leitura, imitando a dislexia. Desse modo, os dois distúrbios podem coexistir ou ocorrer de forma independente.

Os problemas de processamento auditivo também ocorrem com certa frequência e interferem na capacidade do cérebro de compreender totalmente o que "ouve". A criança pode não ter problema auditivo, mas pode ter dificuldade na percepção do som que entra no cérebro, uma vez que o córtex cerebral tem dificuldade em processá-lo ou interpretá-lo de maneira que faça sentido.

É importante lembrar que o mecanismo exato subjacente ao distúrbio do déficit de atenção permanece desconhecido, porém, há uma grande certeza a respeito desse distúrbio: ele não é um mau comportamento que depende da vontade, uma falha moral, falta de tentativa ou incapacidade de interessar-se pelo mundo. Além disso, os estudos neurobiológicos mostram que a síndrome tem raízes no sistema nervoso central. No entanto, no século XIX, e antes disso, o "mau" comportamento era visto como defeito moral e o "tratamento" era o castigo físico (Hallowell \& Ratey, 1999, p. 318-319).

Do ponto de vista de Barkley, mencionado por Viaro (2008), os professores geralmente respondem aos problemas desafiadores exibidos pelas crianças portadoras de TDAH passando a ser mais controladores e autoritários com elas e, com o tempo, suas frustrações com tais crianças podem induzir a comportamentos defensivos ainda mais negativos em suas interações. Enquanto não estiverem seguros sobre o quão negativamente as relações inadequadas de professor-aluno afetam a adaptação da criança portadora de TDAH a longo prazo, os docentes, certamente, podem piorar suas próprias relações, empobrecendo suas conquistas sociais e acadêmicas, reduzindo sua motivação para aprender e ensinar na escola e diminuindo sua autoestima. Isso tudo pode resultar no insucesso da criança e, consequentemente, na evasão escolar. Portanto, exigem dos professores paciência, responsabilidade na relação humana e disponibilidade.

Faz-se necessário, portanto, desenvolverum repertório de intervenções para atuar eficientemente no ambiente da sala de aula com a criança portadora de TDAH. Um constante número de atividades deve ser desenvolvido para educar e melhorar as habilidades deficientes dessas crianças. O professor deve estar atento e preparado para receber portadores de TDAH e procurar conhecer melhor o quadro da disfunção e procurar ajuda e apoio junto à equipe pedagógica, especialistas, médicos e pais para, assim, buscar estratégias que ajudem no desenvolvimento da criança com TDAH.

Goldstein, citado por Viaro (2008), apresenta as seguintes orientações para desenvolver a atenção e a linguagem da criança com TDAH em sala de aula:

1) proporcionar estrutura, organização e constância (sempre a mesma arrumação das cadeiras, programas diários e regras claramente definidas);

2) colocar a criança perto de colegas que não a provoquem (perto da mesa do professor, na parte de fora do grupo);

3) elogiar, encorajar e ser afetuoso (essas crianças desanimam facilmente);

4) dar responsabilidades que elas possam cumprir, fazendo com que se sintam necessárias e valorizadas; 
5) proporcionar um ambiente acolhedor, demonstrando calor e contato físico de maneira equilibrada;

6) nunca provocar constrangimento ou menosprezar o aluno;

7) favorecer oportunidades sociais e proporcionar trabalho de aprendizagem em grupos pequenos, pois em grupos menores as crianças conseguem melhores resultados;

8) comunicar-se com os pais da criança porque, geralmente, eles sabem o que é melhor para o seu filho;

9) diminuir o ritmo do trabalho e parcelar as tarefas (tarefas de cinco minutos cada trazem melhores resultados do que duas tarefas de meia hora);

10) adaptar suas expectativas relativas à criança, levando em consideração as diferenças e inabilidades decorrentes do TDAH;

11) recompensar os esforços, a persistência e o comportamento bem sucedido ou bem planejado;

12) proporcionar exercícios de consciência e treinamento dos hábitos sociais da comunidade (uma avaliação frequente sobre o comportamento da criança consigo mesma e com os outros, ajudará bastante);

13) estabelecer limites claros e objetivos;

14) facilitar o frequente contato aluno/ professor, pois auxilia em um controle extra sobre a criança e possibilita oportunidades de reforço positivo e incentivo a um comportamento mais adequado.

Não obstante, existem outros autores que também apresentam suas estratégias para aplicação de situações que envolvem o melhor desempenho da criança em sala de aula ou na sua vida diária. Construir estratégias constitui um processo ativo de constantes modificações e ajustes e que envolve, esforço, dedicação, trabalho e estudos. Hallowell e Ratey (1999, p. 304-317) apresentam cinquenta sugestões para a gerência do transtorno em sala de aula. É importante ressaltar que o trabalho do professor em uma turma que possua três alunos com diagnóstico desse transtorno pode ser extremamente cansativo, principalmente se essas crianças apresentam outros problemas médicos associados. Por isso, é preciso consultar um especialista, buscar auxílio e apoio com outros profissionais, manter contato constante com a família, apresentando os sucessos e ou insucessos. Assegurar-se que o que se faz é um esforço coletivo, reconhecendo os limites, etc., facilitará o desempenho do professor, a relação com o aluno e, principalmente, o desenvolvimento da criança.

\section{Discussáo}

Dentro das condições estudadas anteriormente, a criança com o TDAH poderá desenvolver e apresentar dificuldades no âmbito social e escolar, porque não processa adequadamente o que está sendo dito ou percebido. Além do mais, os problemas de processamento auditivo interferem profundamente no aprendizado e na interação com as outras pessoas de seu convívio cotidiano. Um distúrbio de aprendizagem, seja qual for sua definição ou causa, geralmente provoca sofrimento, principalmente quando é composto por rótulos (estúpido, preguiçoso e outra denominação semelhante) e a autoestima, corre o risco de ficar seriamente abalada. As pessoas com dislexia e TDAH, ao mesmo tempo, são frequentemente as mais criativas e intuitivas e podem se sair muito bem em algumas de suas habilidades (Hallowell \& Ratey, 1999).

Para Rohde (2003), citado por Viaro (2008), os fatores etiológicos sobre o transtorno do déficit de atenção e hiperatividade são heterogêneos, abrangem fatores genético-familiares, adversidades biológicas e psicossociais. Complicações durante o parto como: pós-maturidade fetal, duração prolongada do parto, sofrimento fetal, baixo peso ao nascer e hemorragia pré-parto trazem resultados de forte influência para indicar o TDAH. Os estudos apontam fatores ambientais como causa do TDAH: os desentendimentos familiares, presença de transtornos mentais nos pais, baixo nível de educação materna, pobreza, filhos de pais solteiros, conflito paternal crônico, abuso sexual e outros trazem grande influência no diagnóstico da vida da criança.

O distúrbio do déficit de atenção se localiza na biologia do cérebro e do sistema nervoso central com um mau funcionamento desses sistemas, provocando comportamentos de hiperatividade, distraimento e impulsividade. C. Kornetsky (1970), 
mencionado por Hallowell \& Ratey (1999), propôs a Hipótese de Catecolamina (compostos que incluem os neurotransmissores norepinefrina e dopamina), em que concluiu que o DDA talvez fosse provocado por uma baixa produção ou uma subutilização desses neurotransmissores (Hallowell \& Ratey, 1999).

A região frontal do cérebro é a principal reguladora do comportamento, onde mantém os impulsos sob controle, sintetiza as informações sensoriais e cognitivas, orquestra a atenção e funciona como o portal das nossas ações. Segundo Chelune (1986), citado por Hallowell \& Ratey (1999), é no córtex do lobo frontal que está a ação no DDA. De acordo com essa hipótese, o cérebro perde a capacidade de "pisar nos freios" de maneira satisfatória, em virtude de uma perturbação nos processos inibitórios do córtex do cérebro, sem a inibição o cérebro não é capaz de bloquear as respostas impróprias, deixando de enviarmensagens inibitórias. As áreas pré-frontais do cérebro são ricas em catecolaminas, um problema no uso dessas, pode estar relacionado à falta de controle de impulsos, atenção e aprendizagem. A dopamina forma um caminho entre o centro motor e as regiões frontais do cérebro e outro do centro límbico às regiões frontais do cérebro. Os neurônios de dopamina dessas áreas inferiores atravessam o lobo frontal central e alcançam o córtex pré-frontal, isso sugere que a dopamina desempenha o papel de conectar a atividade motora, a emoção, a atenção e o controle dos impulsos (Hallowell \& Ratey, 1999).

Por isso, o tratamento utilizado para o TDAH, envolve uma abordagem múltipla, englobando intervenções psicossociais e psicofarmacológicas. No âmbito das intervenções psicossociais, elas devem ser educacionais, por meio de informações claras e precisas a respeito do transtorno. Muitas vezes, é necessário um programa de treinamento para os pais, com ênfase em intervenções comportamentais, a fim de que aprendam a lidar com os sintomas dos filhos. É importante que eles conheçam as melhores estratégias de organização e planejamento das atividades cotidianas de seus filhos (por exemplo, essas crianças precisam de um ambiente silencioso, consistente e sem maiores estímulos visuais para estudar) (Rohde et al., 2000).

$\mathrm{Na}$ prática pedagógica, é importante que o aluno com TDAH receba o máximo possível de atendimento individualizado, visando a incentivar seu desempenho e a melhorar sua autoestima de tal forma que, mesmo a passos lentos, aprenda a tornar aquilo que faz em algo significativo, prazeroso, com sabor de conquista.

Conforme Rohde (2003), citado por Viaro (2008), a criança com TDAH apresenta um transtorno no qual sua maior característica é impulsividade, desatenção e hiperatividade e o papel da escola é de extrema importância. O comportamento do professor, perante a criança com diagnóstico de TDAH, influencia certamente o sucesso do tratamento. Em todos os casos, face à inadequação escolar, deve-se levar em conta os três parceiros - a criança, a sua família e a escola - e tentar avaliar sua interação recíproca, bem como considerar o auxílio terapêutico. Os profissionais que trabalham em ambiente escolar, quando se deparam com situações de crianças com TDAH, devem desenvolver sua função em equipe, pois é necessária a colaboração entre os integrantes da instituição, como fator importantíssimo para que haja mudanças nas estratégias de ensino de todos os envolvidos.

Lembramos ainda que o processo de aprendizagem pode ocorrer dentro e fora da escola, sob forma de conhecimentos. Os pais geralmente se sentem responsáveis pelas condições emocionais, educacionais e comportamentais de seus filhos. $\mathrm{O}$ conhecimento de que a doença decorre de disfunções de áreas cerebrais específicas, ajuda-os a amenizar suas sensações de culpa, tornando-os parceiros na execução de estratégias que possam colaborar para a melhoria do desempenho acadêmico e dos relacionamentos familiares e sociais da criança.

SegundoMuniz,mencionadoporRubinstein (1999), existem vários profissionais que trabalham com o tema da aprendizagem humana. Esse tema oferece um campo de intervenção, cujos limites são amplos. O próprio processo humano de aprendizagem constitui um fenômeno complexo que envolve múltiplos fatores e desafia qualquer tentativa de explicação a partir de um discurso científico único.

Diferentes abordagens teóricas contribuem, com seus esforços, para a construção de um referencial que explique esse processo e sustente práticas que tornem compatíveis as demandas sociais e o desenvolvimento dos indivíduos.

Rubinstein (1999) comenta que houve um longo processo histórico envolvido com o estudo da natureza da aprendizagem; várias correntes se dispuseram a trabalhar este tema, desde a idealista, a "inconformista" e posteriormente vieram os testes, os métodos científicos, a reeducação, a "ultrapedagogia", 
os diagnósticos médicos (os distúrbios de aprendizagem), etc. Muitas das diferentes ciências buscaram recursos que embasassem sua prática. A medicina desenvolveu um papel importante, observando, classificando e dando nomenclatura aos fenômenos do fracasso escolar. Assim, iniciou a reeducação, área do conhecimento preocupada em detectar e tratar as dificuldades de aprendizagem, para construir um plano de trabalho mais orientado. Essa modalidade terapêutica enfatizava os recursos pedagógicos que melhor pudessem auxiliar o aluno com dificuldades. Chassagny, em 1977, citado por Rubinstein (1999), refere-se a essa modalidade como "ultrapedagogia", entendendo que essa denominação está relacionada com paradigmas de uma sociedade industrializada que buscava o controle de qualidade, a padronização da educação, repercutindo na avaliação e no tratamento das dificuldades de aprendizagem.

Um dos objetivos do tratamento era fazer com que os protagonistas do fracasso alcançassemuma melhor adaptação escolar e bons resultados nos testes, quando foram avaliados no início do tratamento, para comprovar a sua eficiência. Alguns dos reeducadores observaram que a superação das dificuldades ocorria não somente graças aos exercícios, mas principalmente pela relação que se estabelecia entre o "terapeuta e o paciente" e entre o paciente e sua produção. Quando havia implicação do sujeito com a proposta, as mudanças eram desencadeadas.

No ambiente educacional, muitas vezes os profissionais envolvidos voltam seus olhos apenas para as dificuldades na área da leitura e da escrita, fundamentalmente usadas pela escola para lidar com o conhecimento. A linguagem tem o seu papel de destaque porque é o veículo pelo qual o fracasso se manifesta. A grande maioria dos problemas de aprendizagem se manifesta por meio da linguagem e, desse modo, deve-se contextualizá-los na relação do sujeito com esse conhecimento. A relação educacional envolve uma relação transferencial entre os envolvidos e ela faz parte da intervenção, produzindo efeitos. Além disso, quando o educador acredita na possibilidade de o aprendiz mudar, as transformações têm mais chances de ocorrer. Não é suficiente querer e acreditar para que sejam possíveis, porque nem todos podem e querem se modificar. A condição paradoxal entre aceitar o limite imposto e desejar a mudança é considerada pelos autores como o ponto de partida que permitirá mobilizar o sujeito (aprendente) a sair do “aprisionamento" (menoridade intelectual) que o transtorno ou distúrbio impõe.

Segundo Feuerstein (1980), citado por Rubinstein (1999), a condição permanente do ser humano é a capacidade de mudança como condição vital de adaptação para manter o seu equilíbrio.

As pessoas que vivenciam o fracasso escolar vêm marcadas por múltiplos insucessos nos vários lugares que ocupam: na família, na escola, no grupo social, etc., onde percebem que não dão conta de responder às expectativas dos outros, estando sempre aquém. Ou são constantemente criticadas, ou se autocriticam. Ao se colocar em uma posição de "tolerância" ativa, o profissional da educação acolhe a performance possível em um determinado momento e investe em uma mediação bem conduzida, de qualidade, para acionar, desenvolver, desencadear o potencial de aprendizagem, que, por muitas razões, não se manifesta. No olhar educacional, o aluno também pode aprender a se ver diferente e ter mais chances de sair do lugar em que o puseram ou no qual ele próprio se colocou. A nova perspectiva de ser "modificado" pela educação por meio da aprendizagem veio das ideias de Pain (1996), conforme os escritos de Rubinstein (1999), onde o objetivo das práticas educacionais é devolver para a criança o anseio por saber, pois em algum lugar ela o perdeu.

Acredita-se que, tendo por base esse princípio, o desejo de saber é algo inerente à espécie humana. A cultura grega defendeu amplamente esses conceitos, que ainda são propagados na atualidade. É necessário resgatar algo que existe, mas por diversas razões não se manifestou no momento. $\mathrm{O}$ resgate do anseio por saber é uma alavanca fundamental para a construção dos sujeitos que lidam com o conhecimento e estendemos aqui a importância dos objetos necessários para o aprendente.

O conhecimento não é algo inerente ao ser humano, já determinado, mas algo que se desenvolve em uma relação de amizade ao saber. A aprendizagem tem a função de introduzir o sujeito na cultura. É fundamental conhecer e compreender o processo de aprendizagem para compreender as dificuldades e as modalidades de intervenção.

Utilizamos, na construção dos nossos argumentos, a definição de aprendizagem proposta por Eliana Dabas (1988), citada por Rubinstein (1999), como um processo pelo qual um sujeito interage com o meio, incorpora a informação oferecida por este, segundo suas necessidades e interesses. Elabora 
essa informação por meio de sua estrutura psíquica, constituída pelo interjogo do social, da dinâmica do inconsciente e da dinâmica cognitiva, modificando sua conduta para aceitar novas propostas e realizar transformações inéditas no âmbito que o rodeia.

Observamos que o reconhecimento de um sujeito/aprendente inserido em um contexto sociocultural se utiliza tanto da objetividade (inteligência) quanto da subjetividade (desejo) para o aprender. O processo de aprendizagem ainda engloba as estruturas orgânica e corporal, qualquer desvio, transtorno no sistema de relações, implica modificações visando ao reequilíbrio e é para essa finalidade que propusemos estudar este tema neste trabalho.

A mesma autora entende que grande parte das dificuldades de aprendizagem se deva à falta de interesse e reduzida necessidade de aprender, o que pode estar relacionado com a natureza das experiências vividas e elaboradas pelo sujeito na relação com o outro. Em síntese, a aprendizagem é um processo complexo, que envolve uma gama de componentes, e compreender as dificuldades de aprendizagem exige capacidade de considerar múltiplos fatores envolvidos para compreender o sujeito cognoscente.

Garcia (1988) comenta que o ser humano é como um centro de perspectiva, as coisas irradiam de si e, ao mesmo tempo em que é o núcleo de seu próprio universo, aquele que acredita ser o ápice da "criação" é o que altera e compromete a natureza, os outros e a si mesmo. Nesse jogo de interpretações, o leva a confundir e a interpretar um fenômeno, porque mescla com seu próprio pensamento refletido.

Além disso, Grevet, Abreu e Shansis (2003) discutem que o TDAH causa grande impacto na vida de seus portadores. Estes apresentam relações interpessoais instáveis e tumultuadas, baixo desempenho escolar, o que acaba por acarretar enormes prejuízos no funcionamento da estrutura familiar e social. Esse impacto é amplificado pelas altas taxas de comorbidades com outras doenças psiquiátricas: Depressão Maior, Transtornos de Ansiedade, Transtornos de Humor Bipolar, Transtornos de Abuso de Substâncias, Transtornos de Personalidade e Alterações de Conduta na idade adulta.

Para eles, os pacientes com TDAH apresentam alterações específicas em uma função cognitiva chamada de Função Executiva (FE). Essa função coordena a memória imediata, memória imediata verbal, autorregulação dos afetos e permite a reconstituição e análise do próprio comportamento. Alterações nessa função podem prejudicar o controle dos impulsos, dificultar a aquisição de informações, interferir nas respostas verbais e no controle motor em relação aos estímulos. Por fim, o TDAH pode ser entendido como o extremo de um comportamento e de um mau funcionamento da FE, uma vez que essa população apresenta um grande número de problemas na área dos processos de ensino/aprendizado, o que acarreta dificuldade na aquisição de novos conteúdos.

Fica muito complexo discutir a dificuldade de concentração e atenção e a tendência à desorganização do pensamento das crianças com TDAH. Graeff e Vaz (2006) comentam que as crianças com TDAH apresentam dificuldades de percepção objetiva da realidade, de sistematização e de concentração, tendência a realizar as tarefas de forma rápida e superficial quando comparadas às crianças normais. A dificuldade que essas crianças têm de usar a razão, assim também como o pensamento lógico, as falhas no controle geral e a elevada impulsividade, acabam por afetar o controle das reações emocionais, prejudicando o funcionamento do indivíduo como um todo, repercutindo na aquisição de novos conhecimentos.

Nessa perspectiva "existencial" da criança com TDAH, cabe salientar que a natureza motivacional e a sensorial constituem fatores importantes que determinam ouniverso humano. A natureza sensorialo limita a perceber por completo as alterações do ambiente influenciando em sua resposta ao meio. Há um universo invisível a ser ampliado, situado além de seus sentidos, mundo esse que se esconde de um lado e outro de seus limiares específicos, culminando em filtração periférica de estímulos porque nem todas as alterações ambientais podem desencadear alguma resposta no organismo, e ainda porque se dá no nível de receptores específicos do seu equipamento sensorial (Garcia, 1988).

A natureza das alterações comportamentais (previstas pela motivação), e também suas causas, tanto ambientais quanto fisiológicas ou neurológicas, implica mudanças na responsividade de um organismo diante de uma condição estimulatória, significando mudanças temporárias - ao contrário da aprendizagem, que implica mudanças permanentes, mais ou menos duradouras; ela é exaustivamente analisada e entendida como alterações capazes de levar o homem a perceber algumas classes de eventos com maior clareza, as nuanças e sutilezas de seus campos de trabalho. Assim, os homens, equipados e limitados, ordenam o 
mundo à sua maneira, classificam e interpretam seus eventos e os seres que o compõem. Qualquerconclusão deve ser entendida como maneira particular de ver o mundo que o homem detecta de algum modo e tenta interpretar e esboçar (Garcia, 1988).

Por isso nos preocupamos com a complexidade da questão em entender o universo da criança com TDAH. A aprendizagemé subordinada às capacidades sensoriais detectadas pela criança e depende do estado motivacional do indivíduo, das predisposições genéticas, etc. Por meio de interações com o ambiente, vai sendo modificada e aperfeiçoada segundo um ritmo próprio e característico de cada um, onde o aprender também significa o aprimoramento de algo.

Não há sentido em considerar e valorizar apenas um tipo de habilidade cognitiva da criança com TDAH, em função de suas supostas capacidades intelectuais. Estamos integrados às características do ambiente onde vivemos e às funções que desempenhamos e temos um equipamento orgânico e comportamental que nos permite buscar a sobrevivência, fatores esses que, somados, fazem com que nos tornemos seres únicos e singulares e que, por meio do simbolismo, nos construímos mesmo diante das dificuldades.

\section{Consideraçóes finais}

O transtorno de déficit de atenção e hiperatividade somente pode ser diagnosticado clinicamente e pode comprometer de modo marcante a vida da criança em fase escolar e dos adolescentes e dos familiares que os cercam, pois essa condição promove dificuldades como controle dos impulsos, concentração, memória, organização, planejamento e autonomia, entre outras. Envolve uma grande pluralidade de dimensões associadas, tais como comportamentais, intelectuais, sociais e emocionais.

O processo de avaliação diagnóstica é abrangente, envolvendo necessariamente a participação de vários profissionais da área da saúde, escola e familiares. Desse modo, o diagnóstico e o tratamento precoce são imprescindíveis para a prevenção de distúrbios associados, como os de conduta, delinquencia e outras comorbidades da criança e ou adolescente, evitando prejuízos no processo de desenvolvimento da vida social e intelectual.

No TDAH, sendo considerado como uma síndrome heterogênea, envolvendo fatores genéticos, biológicos, psicossociais e ambientais, faz-se necessária uma contextualização dos sintomas para um possível diagnóstico, tratamento e intervenções psicopedagógicas, que dependerão do grau do problema. Sendo uma síndrome de origem genética , em que o sistema biológico passa por uma mudança neuroanatômica ou maturacional, provoca o desequilíbrio, a desregulação do sistema neurobiológico do corpo, prejudicando a capacidade da criança em prestar atenção seletiva ao que a cerca. Os sinais de que os sistemas neuroquímicos são alterados em pessoas com TDAH são suficientes para que se possa afirmar que o problema deriva da química do cérebro, em que há uma desregulação ao longo do eixo catecolamina-serotonina. Há casos em que as crianças podem ser tratadas apenas com terapia comportamental e, em situações mais graves, deve haver uma ação multidisciplinar, englobando os pais, professores, médicos e a utilização de medicamentos.

Os medicamentos empregados para trataro TDAH promovem uma melhora no funcionamento e no uso dos neurotransmissores nas regiões frontais do cérebro, proporcionando um maior controle desses sistemas com a finalidade de corrigir os processos de atenção desregulados e desacelerar o fluxo de vida acelerado. Os medicamentos normalmente usados incluem os estimulantes ritalina e dexedrina, que agem nos sistemas da catecolamina e da serotonina, sendo os efeitos mais marcantes na norepinefrina. As drogas aumentam os níveis dos neurotransmissores, proporcionando uma maior disponibilidade do neurotransmissor em questão para uso do cérebro.

São fundamentais as intervenções pedagógicas para o desenvolvimento da aprendizagem das crianças e adolescentes na fase escolar, durante o tratamento do TDAH, por meio de atividades didático-pedagógicas diferenciadas para esse aluno, visando a estimular sua autoestima.

\section{Referências}

Benczik, E. B. P. (2008). Transtorno de Déficit de Atenção/Hiperatividade-Atualização Diagnóstica e Terapêutica: Um guia de orientação para profissionais (4a ed.). São Paulo: Casa do Psicólogo. Recuperado em 24 nov. 2009, em, http://books. google.com/books?id=AeTN3wMqRwC\&printsec $=$ frontcover $\& \mathrm{dq}=$ hiperatividade $\& \mathrm{hl}=\mathrm{ptBR} \#_{\mathrm{v}}=$ on epage $\& \mathrm{q}=\& \mathrm{f}=$ fals

Garcia, F. L. (1988). Introdução crítica ao conhecimento. Campinas, SP: Papirus. 
Graeff, R. L., \& Vaz, C. E. (2006). Personalidade de crianças com Transtorno de Déficit de Atenção e Hiperatividade (TDAH) por meio do Rorschach. Psicologia: Teroria e Pesquisa, 22(3), 269-276. Recuperado em 29 dez. 2009, em http://www.scielo.br/scielo.php?pid=S0102$-37722006000300003 \&$ script $=$ sci_abstract\&tlng $=$ pt

Grevet, E. H., Abreu, P. B., \& Shansis, F. (2003). Proposta de uma abordagem psicoeducacional em grupos para pacientesadultoscom Transtorno deDéficitde Atenção/ Hiperatividade. Revista de Psiquiatria do Rio Grande do Sul, 25(3), 446-452. Recuperado em 29 dez. 2009, em http://www.scielo.br/scielo.php?pid=S0101-81082003000300006\&script=sci_arttext\&tlng=es

Hallowell, E. M., \& Ratey, J. J. (1999). Tendência à distração: Identificação e gerência do distúrbio do déficit de atenção da infância à vida adulta. Rio de Janeiro: Rocco.

Rohde, L. A., Barbosa, G. A., Tramontina, S., \& Polanczyk, G. (2000). Transtorno de déficit de atenção e hiperatividade. Revista Brasileira de Psiquiatria, (Supl. II). Recuperado em 10 jun. 2009, em, http://www. scielo.br/pdf/rbp/v22s2/3788.pdf

Rohde, L. A., \& Halpern, R. (2004). Transtorno de déficit de atenção/hiperatividade. Jornal de Pediatria, 80(2). Recuperado em 3 out. 2009, em http:// www.scielo.br/scielo.php?script $=$ sci_arttext\&pi $\mathrm{d}=$ S0021-75572004000300009

Rubinstein, E. (1999). Psicopedagogia: Uma prática, diferentes estilos. São Paulo: Casa do Psicólogo. Recuperado em 29 dez. 2009, em http://books. google.com.br/books?hl=pt-BR\&lr=\&id $=4 \mathrm{MqVQ}$ 4f3K2IC\&oi $=$ fnd $\& p g=$ PA9 $\&$ dq $=$ psicopedagogia + Rubinstein\&ots=2PIInmQZ_Y\&sig=QJLP_4Er ssaPE2vr6g_Z6TvuHLw\# ${ }_{\mathrm{v}}={ }_{\text {onepage } \& \mathrm{q}}=\& \mathrm{f}=$ true

Viaro, C. D. F. (2008). A criança com transtorno de atenção e hiperatividade: $O$ papel da escola e do educador, sua influência e motivação no ensino-aprendizagem. Monografia, Curso de Especialização lato-senso em Distúrbio de Aprendizagem. Didática, São Paulo.

Recebido: 20/06/2010

Received: 06/20/2010

Aprovado: 05/10/2010

Approved: 10/05/2010 